\title{
CB1 Cannabinoid Receptor Activation Inhibits a Neural Correlate of Song Recognition in an Auditory/Perceptual Region of the Zebra Finch Telencephalon
}

\author{
Osceola Whitney, ${ }^{1}$ Ken Soderstrom, ${ }^{2}$ Frank Johnson ${ }^{1}$ \\ ${ }^{1}$ Department of Psychology and Program in Neuroscience, Florida State University, Tallahassee, \\ Florida 32306-1270 \\ 2 Department of Pharmacology and Toxicology, Brody School of Medicine, East Carolina University, \\ Greenville, North Carolina 27834
}

Received 12 November 2002; accepted 13 February 2003

\begin{abstract}
A notable consequence of CB1 cannabinoid receptor activation in vertebrates is an impairment of cognitive function related to learning and shortterm memory. The mechanisms of this impairment remain unclear, but one possibility is that cannabinoids influence encoding of stimuli at sensory and/or perceptual levels. Here, by treating zebra finches with the cannabinoid agonist WIN55212-2 and then measuring expression of the transcription factor zenk following presentation of novel zebra finch song, we show that cannabinoid receptor activation differentially influences zenk expression in sensory versus perceptual regions of the songbird auditory telencephalon. That is, WIN55212-2 dose-dependently inhibited zenk expression in a region for auditory perception (NCM, the
\end{abstract}

caudomedial neostriatum), but had no effect on zenk expression in the primary auditory area, the Field $\mathbf{L}$ complex. The inhibitory effects of WIN55212-2 on zenk expression in NCM were reversed by coadministration of the CB1-selective antagonist SR141716A. Moreover, we found that the habituation of the NCM zenk response to repeated presentation of the same song, a well-established neural correlate of song recognition, was blocked when birds were treated with WIN55212-2 during habituation trials. Our data suggest that activation of CB1 cannabinoid receptors can selectively influence perceptual and mnemonic aspects of auditory experience. () 2003 Wiley Periodicals, Inc. J Neurobiol 56: 266-274, 2003

Keywords: songbird; immediate early gene; zenk; NCM; auditory perception; CB1 cannabinoid receptor

\section{INTRODUCTION}

In the songbird telencephalon, auditory perception is associated with neural activity in NCM, as evidenced by activation of the transcription factor zenk (Mello

Correspondence to: O. Whitney (E-mail: owhitney@ psy.fsu.edu).

Contract grant sponsor: NIH; contract grant numbers: DC02035 (to F.J.) and DA05986 (K.S.).

(C) 2003 Wiley Periodicals, Inc.

DOI $10.1002 /$ neu. 10233 and Clayton, 1994). Maximal zenk induction within NCM is observed in response to playback of a novel conspecific song, with muted responses to heterospecific song or pure tones (Mello et al., 1992). Moreover, repeated playback of the same song causes longlasting habituation of neuronal responses in NCM, accompanied by an habituation of zenk induction (Chew et al., 1995; Mello et al., 1995; Stripling et al., 1997). In canaries, the spatial distribution of zenk expression in NCM after playback of novel conspecific song appears to be topographically organized according to frequency (Ribeiro et al., 1998). Together, these data implicate the NCM zenk response 


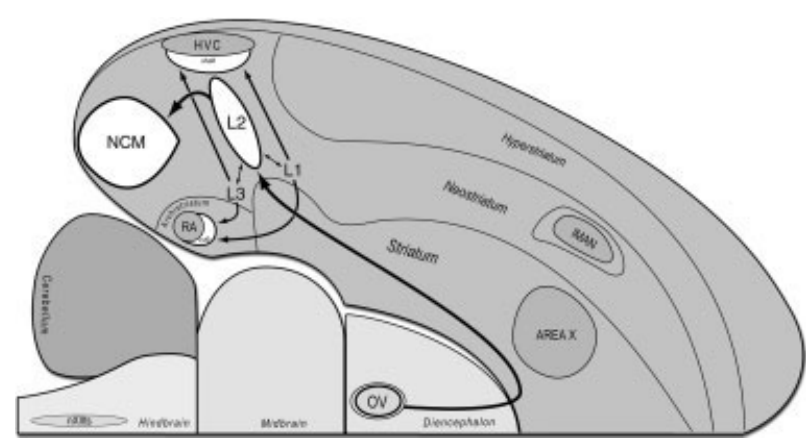

Figure 1 Sagittal schematic of the zebra finch CNS shows relative locations of forebrain auditory structures and their sources of synaptic input. The Field L complex is a primary telencephalic auditory region in birds, and is divided into three laminae (L1, L2, L3; Bonke et al., 1979). Ascending input from the auditory thalamus (OV) terminates mainly within Field L2b, which in turn, is reciprocally connected to L1 and L3 (Vates et al., 1996). NCM received input from Field L2a, and shows selective repsonses to complex auditory stimuli (conspecific song), both in terms of electrophysiology and induction of the transcription factor zenk, but both responses habituate with repeated presentations of song stimuli (reviewed by Clayton, 1997). Fields L1 and L3 both project to the shelf of HVC and the cup of RA, sites in which auditory information may be relayed into nuclei that control vocal production (i.e., HVC, RA, IMAN, Area X, nXIIts; Fortune and Margoliash, 1995; Vates et al., 1996). Abbreviations: Area X, Area X of striatum; HVC, higher vocal center; IMAN, lateral magnocellular nucleus of the anterior neostriatum; NCM, caudomedial neostriatum; OV, nucleus ovoidalis; RA, robust nucleus of the archistriatum; nXIIts tracheosyringeal portion of the hypoglossal nucleus.

in functions specifically related to perceptual and mnemonic aspects of songbird auditory experience (Clayton, 1997).

NCM receives input from L2 of the Field L complex (see Fig. 1). The Field L complex is a primary sensory area for auditory stimuli in the avian telencephalon, receiving ascending input from the avian auditory thalamus (nucleus ovoidalis, see Fig. 1) and showing a tonotopic, frequency-specific neuronal responsiveness in all three subdivisions (L1, L2, L3; Bonke et al, 1979). Thus, presentation of any auditory stimulus (simple or complex) will activate zenk expression in the Field L complex (subdivisions L1and L3; Mello and Clayton, 1994).

Using Northern blot analysis and RT-PCR, we have found that the caudal telencephalon of the zebra finch, which includes Field L and NCM, shows robust expression of CB1 cannabinoid receptor mRNA (Soderstrom and Johnson, 2000). We have also found that the pharmacology of zebra finch CB1 is remarkably similar to that of mammals (Elphick and Egertova,
2001; Soderstrom and Johnson, 2001). Telencephalic expression of CB1 has been observed in every vertebrate species studied to date, from an amphibian (Soderstrom et al., 2000) to humans (Herkenham et al, 1990), data that provide anatomical support for the widely known effects of cannabinoid agonists on a variety of higher CNS functions, most notably cognitive performance and voluntary motor control (for reviews, see Chaperon and Thiebot, 1999; Sullivan, 2000; Elphick and Egertova, 2001). However, sites of action within the telencephalon as well as underlying physiological mechanisms remain to be established, although cannabinoid inhibition of neural activity in mammalian hippocampus appears to contribute to cannabinoid impairment of cognitive processes related to short-term memory (Hampson and Deadwyler, 2000).

Another mechanism by which cannabinoids could influence cognitive performance is by modulation of sensory and/or perceptual processes. For example, CB1-mediated modulation of sensory input appears to be one mechanism by which cannabinoids inhibit behavioral and cellular responses to noxious stimulation; the cannabinoid agonist WIN55212-2 dose-dependently suppresses pain-evoked electrophysiological activity and expression of the transcription factor c-fos within the rat spinal cord (Hohmann et al., 1995; Tsou et al., 1996). However, the possibility that cannabinoids could also influence processing of noxious stimuli by acting on sensory or perceptual mechanisms in the telencephalon remains to be evaluated.

No current model for the study of cannabinoid pharmacology has been used to test for differential effects of cannabinoids on sensory versus perceptual processes in the telencephalon, as this requires distinction between cannabinoid effects on the primary encoding of sensory information versus the higher order integration of sensory attributes. Here, we have used expression of the zenk transcription factor in Field L and NCM of zebra finches, induced by presentation of a novel song, to distinguish cannabinoid effects on sensory versus perceptual processes in the songbird auditory telencephalon. Our findings show that WIN55212-2 treatment dose-dependently inhibits novel song-induced zenk expression in a region for song perception (NCM), but has no effect on zenk expression in the primary auditory region Field L. We also show that WIN55212-2 treatment blocks a neural correlate of recognition memory in NCM, namely, habituation of the zenk response in NCM to repeated presentation of the same song. Together, our results indicate that CB1 cannabinoid receptor activation inhibits gene expression associated with song recogni- 
tion at perceptual but not sensory levels of auditory processing.

\section{MATERIALS AND METHODS}

\section{Animals}

The Florida State University Animal Care and Use Committee approved all protocols and procedures. Adult zebra finches (Taeniopygia guttata) used in this study were obtained from our breeding colony at FSU. All birds $(n=47)$ were $>120$ days old.

\section{Apparatus}

For this study animal housing was built to order by the FSU Neuroscience Program engineering personnel. Twenty-four hours before the start of the experiment subjects were removed from the flight aviary and individually housed in a boxed compartment of clear acrylic plastic and plastic grating $(53 \times 27 \times 28 \mathrm{~cm})$. This enclosure was placed within a computer-operated environmental chamber. Within this controlled setting 24-h ambient temperature was held at 26 $\pm 2^{\circ}$ and an incandescent bulb (illuminance $\sim 60 \mathrm{~lx}$ of 2250 $\mathrm{K}$ light measured near the center of the chamber) maintained a 14-hr photoperiod that began at 8 a.m. Birds inside the chamber roamed freely in acoustic and visual isolation, with ad libitum access to fresh SunSeed VitaFinch seed mix (Bowling Green, OH, www.sunseed.com) and local tap water. Environmental chambers were fitted with speakers linked to a computer programmed to play a recording of a novel zebra finch song to induce expression of zenk in the auditory telencephalon.

\section{Induction of Zenk Expression in the Songbird Auditory Telencephalon}

An established protocol (Mello and Ribeiro, 1998) was used to induce zenk protein expression within zebra finch auditory telencephalon. Thirty minutes after injections, birds were exposed to playbacks of a digital recording of three different zebra finch song bouts (each bout lasted a total of $5 \mathrm{~s}$ ) that were novel to the subjects in our study. Consecutive presentation of all three song bouts was followed by $45 \mathrm{~s}$ of silence. This procedure (15 s of song, $45 \mathrm{~s}$ of silence) was repeated 30 times.

\section{Drug Preparation and Administration}

The cannabinoid agonist WIN55212-2 and antagonist SR141716A were used in this study. WIN55212-2 was purchased from Tocris Cookson (Ellisville, MO, www. tocris.com) and SR141716A was provided by the National Institute on Drug Abuse (www.nida.nih.gov).

Concentrated stocks of WIN55212-2 and SR141716A dissolved in DMSO were suspended for injection in phos- phate-buffered saline (PBS) and Alkamulus EL-620 (DMSO:Alkamuls:PBS, 1:1:18). Naive birds received injection of cannabinoid or vehicle into the pectoral muscle at 7:30 a.m., $30 \mathrm{~min}$ before exposure to playback of the song stimulus. A WIN55212-2 dose-response experiment employed the following six dosage groups $(n=4$ birds in each): $0.01 \mathrm{mg} / \mathrm{kg}, 0.03 \mathrm{mg} / \mathrm{kg}, 0.1 \mathrm{mg} / \mathrm{kg}, 0.3 \mathrm{mg} / \mathrm{kg}, 1$ $\mathrm{mg} / \mathrm{kg}, 3 \mathrm{mg} / \mathrm{kg}$. To determine whether the inhibitory effect of WIN55212-2 on song-induced zenk immunoreactivity in $\mathrm{NCM}$ was specific to $\mathrm{CB} 1$ receptor activation, birds $(n=3)$ received injections of the $\mathrm{CB} 1$-selective cannabinoid antagonist, SR141716A (3 mg/kg) followed $5 \mathrm{~min}$ later by WIN55212-2 $(1 \mathrm{mg} / \mathrm{kg})$.

After the dose-response experiment we tested whether cannabinoid treatment would disrupt the zenk habituation response to repeated presentation of the same song. On two consecutive mornings adult male birds received a single i.m. injection WIN55212-2 $(n=5)$ or vehicle $(n=5)$ and 30 min later were exposed to a conspecific song stimulus. On the third and final morning of exposure to the song stimulus all birds were injected with vehicle and subsequently processed for zenk immunocytochemistry. A third group of control birds $(n=5)$ received one exposure to the song stimulus after injection of vehicle and were then prepared for immunolabeling of zenk.

\section{Tissue Preparation and Zenk Immunocytochemistry}

All kits and reagents used for immunocytochemistry were purchased from Vector Laboratories (Burlingame, CA, www. vectorlabs.com). Polyclonal Egr-1 C19 antibody was purchased from Santa Cruz Biotechnology (Santa Cruz, CA, www.scbt.com). The specificity of this antibody's interaction with zebra finch zenk has been well established (Mello and Ribeiro, 1998; Kruse et al., 2000).

To prepare for zenk immunocytochemistry birds were overdosed with $80 \mu \mathrm{L}$ of equithesin and perfused with saline followed by $4 \%$ paraformaldehyde 90 min after initiating song playbacks. After the brains were dissected and immersed overnight in $4 \%$ paraformaldehyde, the left telencephalic hemisphere was blocked at its lateral edge and parasagitally sectioned (medial to lateral) at $30 \mu M$ on a vibrating microtome. Zenk immunocytochemistry was performed using a standard protocol reported in Whitney et al. (2000). Briefly, tissue sections were rinsed in $0.1 \% \mathrm{H}_{2} \mathrm{O}_{2}$ for $30 \mathrm{~min}$, blocked with $5 \%$ normal goat serum (NGS) for $35 \mathrm{~min}$, and incubated overnight in an egr-1 antibody solution (1:1000). The following day sections were rinsed in saline, incubated in biotinylated antirabbit solution for $1 \mathrm{~h}$, rinsed with saline again, and then submerged in avidinbiotin-peroxidase complex solution for $1 \mathrm{~h}$. Antibody labeling was visualized with DAB solution. Control sections that were not incubated in primary antibody were not immunoreactive. 


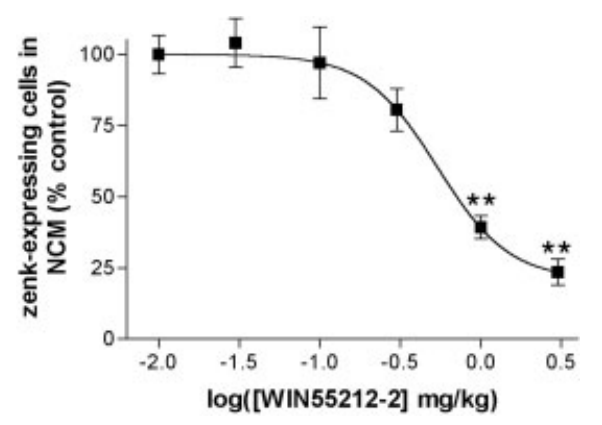

Figure 2 Zenk expression in NCM, induced by playback of a novel conspecific song, is suppressed in a dose-dependent manner by intramuscular injections of the CB1 receptor agonist WIN55212-2. Maximal inhibition $77 \%$ at 3 $\mathrm{mg} / \mathrm{kg}$ WIN $\left(\mathrm{IC}_{50}=0.55 \pm 0.03 \mathrm{mg} / \mathrm{kg}\right)$. WIN55212-2 significantly inhibited zenk expression in both 1 and 3 $\mathrm{mg} / \mathrm{kg}$ dosage groups $(* * p<0.001, \mathrm{SNK})$. Data points are mean \pm S.E.M.

\section{Data Analysis and Statistics}

Data analyses and statistical procedures were performed using PC software Prism GraphPad (San Diego, CA, www. graphpad.com) and Microsoft Excel 2002 (www.microsoft. com/excel). All quantification procedures on individual birds were completed without knowledge of experimental group. The density of zenk immunolabeled cells was measured using previously established procedures (Whitney et al., 2000). Immunoreactive nuclei within $\mathrm{NCM}$ and Field $\mathrm{L}$ were the unit of count within a high power grid defined by $60 \times$ objective (volume $=0.0023 \mathrm{~mm}^{3}$ ). Like Mello and Ribeiro (1998), an inclusive counting criterion was used (all lightly and darkly stained cells were counted). For each bird, three randomly selected high power fields were counted per NCM and Field L in four different tissue sections. The density of zenk labeled cells was defined as the total number of immunoreactive cells counted divided by the volume of the 12 grids. Parasagittal sections of the caudal telencephalon $>0.15 \mathrm{~mm}$ from midline were used to quantify NCM zenk induction. Previous studies show that in this region robust uniform levels of song-induced zenk expression occur within clearly defined boundaries of NCM (Mello and Clayton, 1994; Mello and Ribeiro, 1998). Caudomedial sections $1.4 \mathrm{~mm}$ from midline were used to quantify zenk immunoreactive nuclei within the Field L complex. Each Field L subdivision (L1, L2, L3) was individually quantified.

Zenk expression data are reported as percent of induction relative to control \pm SEM. Nonlinear regression analysis was performed on dose-response data from zenk immunocytochemistry assays. A one-way ANOVA and Student-Newman-Keuls (SNK) post hoc analysis was used to test for between group differences in the density of NCM zenk protein expression for WIN55212-2 dose groups and habituation treatment groups. Single-dose experiments were evaluated with unpaired two-tailed $t$-tests.

\section{RESULTS}

Treatment with the cannabinoid agonist WIN55212-2 reduced novel song-induced zenk immunocytochemical labeling in NCM in a dose-dependent manner, $F(5,26)=18.38, * * * p<0.0001$ (see Fig. 2). Post hoc comparisons showed that the density of zenkexpressing cells in NCM following novel song presentation was significantly reduced in birds that received $1 \mathrm{mg} / \mathrm{kg}$ of WIN55212-2 $(* * p<0.001)$ and 3 $\mathrm{mg} / \mathrm{kg}$ of WIN55212-2 (**p $<0.001)$. In contrast, increasing dosages of WIN55212-2 did not alter the density of zenk-expressing cells that were induced by song-stimulus playbacks in Field L1 and L3 (see Fig. 3 ), indicating that the effects of WIN55212-2 treatment were specific to NCM. Playbacks of the song stimulus never induced zenk protein expression within Field L2 (see Fig. 4).

WIN55212-2 treatment alone had no effect on zenk immunocytochemical labeling. That is, birds treated with WIN55212-2 or vehicle but not exposed to song playbacks showed similar low levels of zenk protein expression in Field L and NCM (see Fig. 4). However, injections of WIN55212-2 at $1 \mathrm{mg} / \mathrm{kg}$ pro-
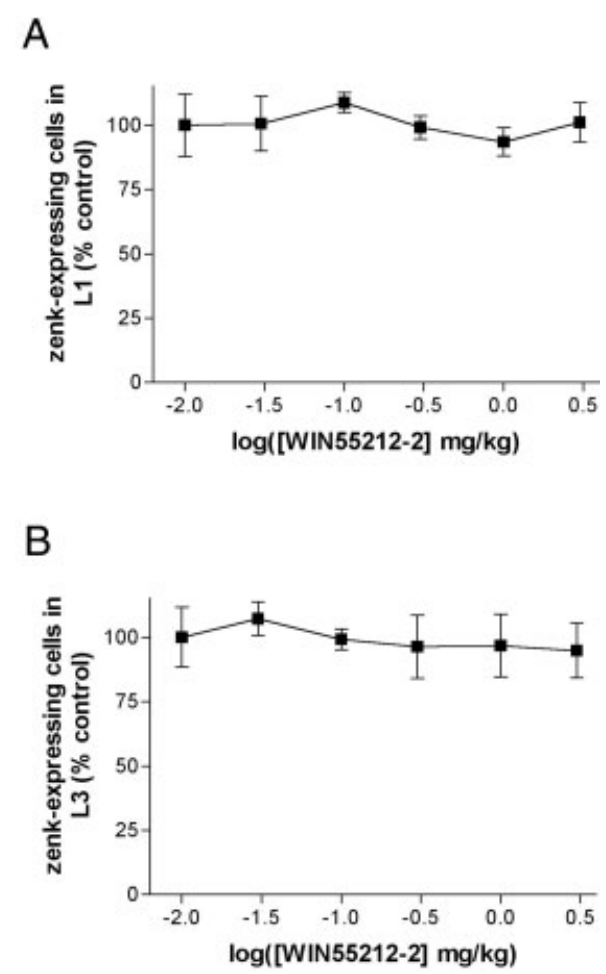

Figure 3 Zenk expression in Field L1 and L3, induced by playback of a novel conspecific song, is not influenced by intramuscular injections of the CB1 receptor agonist WIN55212-2. Data points are mean \pm S.E.M. 

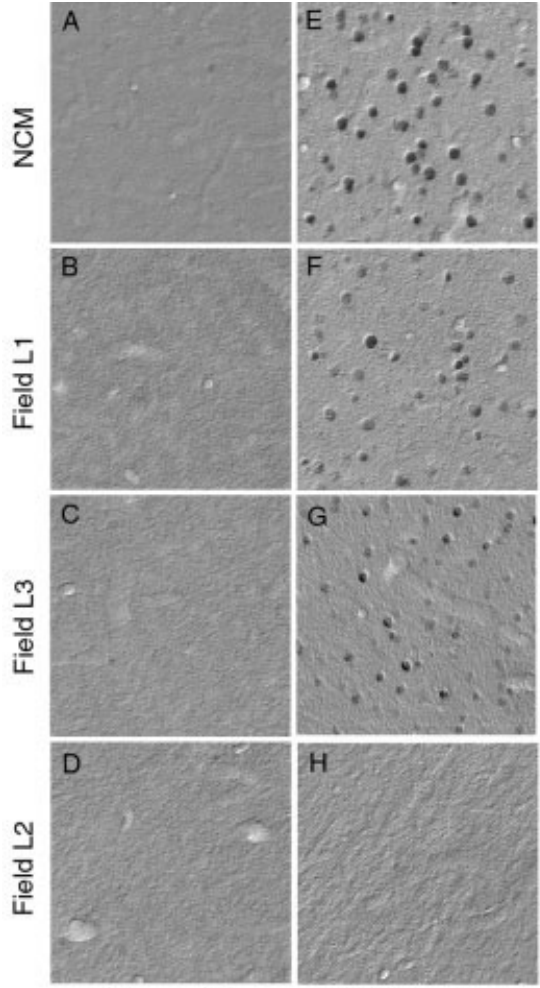

WIN + No Song
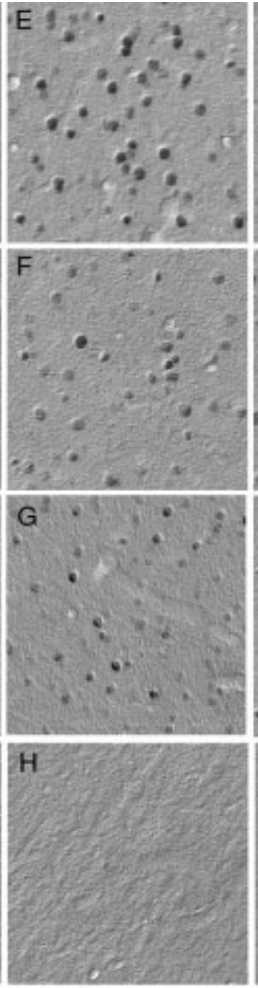

Vehicle + Song
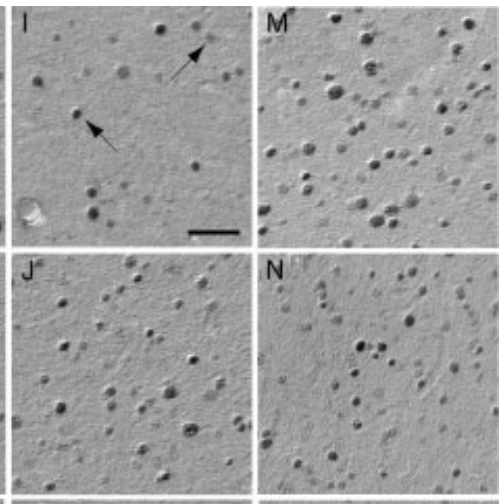
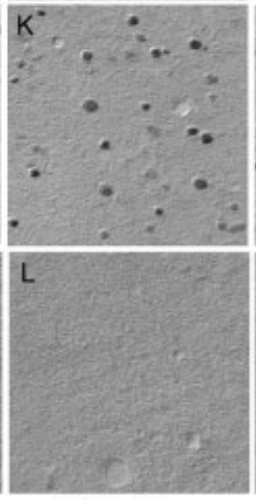

WIN + Song
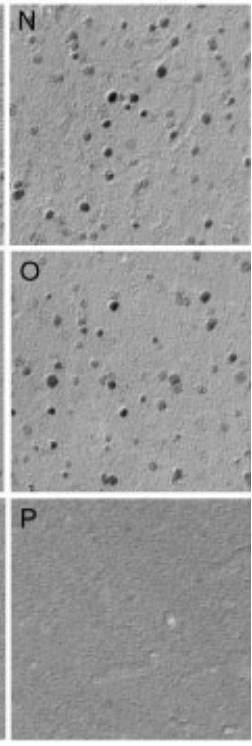

$\mathrm{SR}+\mathrm{WIN}+$ Song

Figure 4 Example photomicrographs of zenk immunolabeling in NCM and the Field L complex show that the inhibitor effects of WIN55212-2 on song stimulus-induced zenk expression are specific to NCM. Treatment with WIN55212-2 alone $(1 \mathrm{mg} / \mathrm{kg})$ had no effect on zenk expression (A-D). Compared to the levels of zenk expression induced by playback of a novel conspecific song in the vehicle-treated birds (E-H), treatment with WIN55212-2 (I-L) specifically inhibited zenk expression in NCM. Coadministration of the CB1 antagonist SR141716A (M-P) reversed the inhibitory effects of WIN55212-2 on zenk expression in NCM, demonstrating specific involvement of the CB1 receptor. Zenk immunolabeling was never observed in Field L2 (D,H,L.P). Examples of zenk immunolabeled cell nuclei are indicated with arrowheads in (I). All photomicrographs were taken with a Sony DKC-5000 digital camera and imported into Adobe Photoshop 4.0 Scale bar in (I) $=60 \mu \mathrm{m}$.

duced a $61 \%$ reduction in the number of song-stimulated zenk labeled cells in NCM, $t(9)=6.35 ; * * p$ $<0.0001$ (see Figs. 4 and 5). WIN55212-2 suppression of zenk labeling in NCM was reversed with the CB1-specific antagonist SR141716A at $3 \mathrm{mg} / \mathrm{kg}$ [see Fig. $4 ; t(5)=9.81 ; * * *<0.0002]$. Antagonist reversal was to levels indistinguishable from vehicle controls. Cannabinoid effects on zenk labeling were specific to NCM; within regions involved in primary sensory processing (Field L1 and L3), densities of zenk-labeled cells did not vary as a function of SR141716A and/or WIN55212-2 treatment (see Figs. 4 and 5).

WIN55212-2 treatment also blocked the habituation of the zenk response following 3 consecutive days of exposure to song-stimuli, $F(3,14)=22.81$, ${ }^{* * *} p<0.0001$ (see Fig. 6). The density of zenk labeled cells in NCM of birds treated with WIN55212-2 on the first 2 days of song exposure and vehicle on the third day was significantly higher than that of birds who received vehicle injections on all 3 days of song exposure $\left({ }^{* *} p<0.001\right)$, whereas the zenk response in birds treated with WIN55212-2 during the habituation protocol did not differ from that of birds given vehicle and exposed to a single presentation of novel song (see Fig. 6). For all groups, there were no differences in zenk expression in Field L.

\section{DISCUSSION}

Our findings indicate that activation of CB1 cannabinoid receptors selectively modulates neural activity 
A

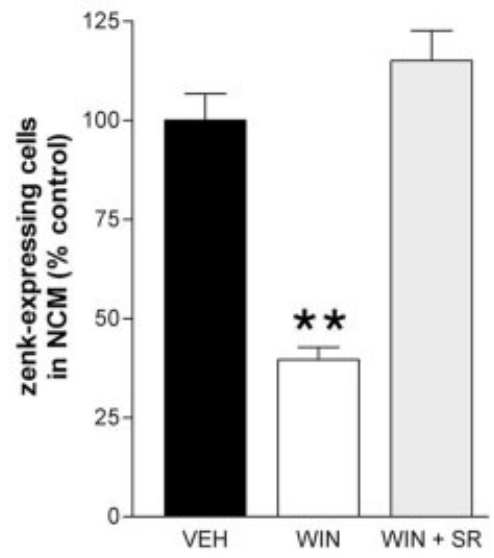

B

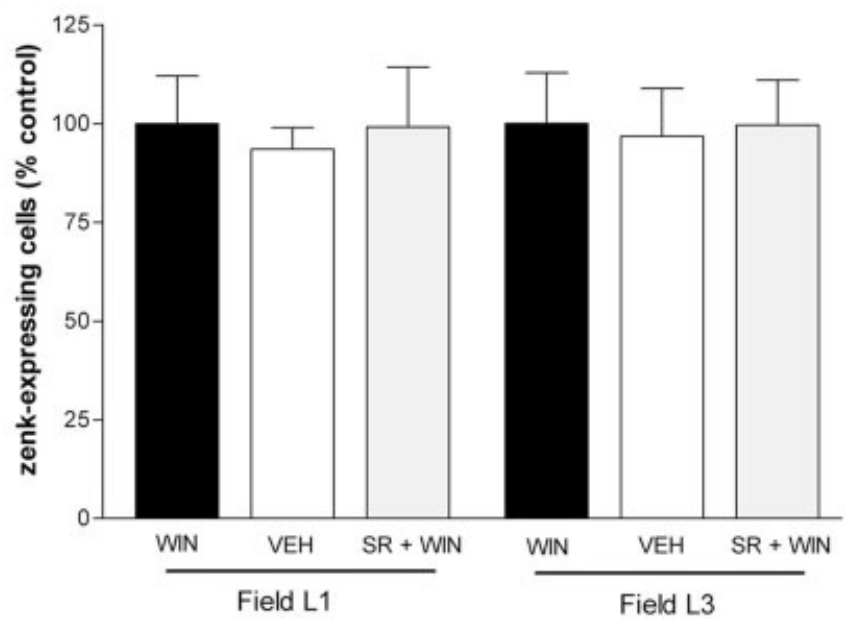

Figure 5 Inhibition of song stimulus-induced zenk immunoreactivity in NCM is reversed with the CB1 receptor antagonist SR141716A. (A) The 61\% reduction in zenk immunoreactivity in NCM of brids treated with $1 \mathrm{mg} / \mathrm{kg}$ of WIN55212-2 $(* * p<0.001$, SNK) was completely reversed with 3 $\mathrm{mg} / \mathrm{kg}$ of SR141716A, demonstrating that the inhibitory effects of WIN55212-2 treatment of zenk immunoreactivity are due to specific activation of the CB1 cannabinoid receptor. (B) Song stimulus-induced zenk immunoreactivity in Field L1 and L3 of birds treated with both SR141716A and WIN55212-2, was comparable to zenk immunoreactivity in Field L of birds treated with WIN55212-2 alone as well as vehicel controls. Histogram bars are means + S.E.M.

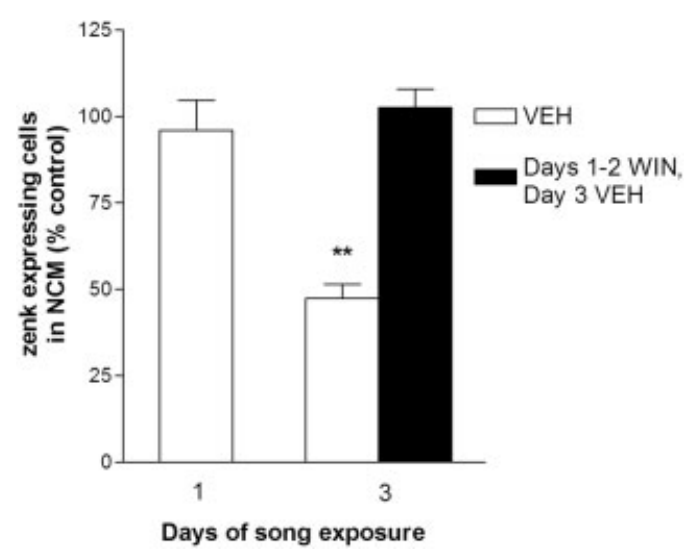

Figure 6 WIN55212-2 treatment blocks the normal habituation of the NCM zenk response to repeated presentation of the same song. Although birds treated with vehicle and exposed to the same song stimulus on 3 consecutive days showed a marked $53 \%$ reduction in the density of zenk immunoreactive cells in NCM, brids treated with WIN55212-2 on the first 2 days of song exposure and vehicle on the third day of song exposure (black bar) showed an NCM zenk response that was comparable to the "novelty" response seen in vehicle-treated birds that received only 1 day of song exposure. Histogram bars are means + S.E.M. associated with auditory perception and recognition memory. Cannabinoid administration inhibited songinduced zenk expression in an auditory region for song perception (NCM), but had no effect on songinduced zenk expression in the primary auditory area Field L. This selective modulation of zenk expression in NCM was dose dependent and reversible with the CB1-selective antagonist, SR141716A, implicating CB1 cannabinoid receptor involvement. Moreover, habituation of the NCM zenk response to repeated presentation of the same song, a neural correlate of recognition memory, was blocked by administration of WIN55212-2.

Brain region-specific inhibition of song-induced zenk expression likely involved reduced neuronal activity within NCM caused by $\mathrm{CB} 1$ receptor activation. Increasing evidence suggests that $\mathrm{CB} 1$ receptor-effected reductions in neuronal activity may involve inhibition of presynaptic calcium channels, leading ultimately to decreased neurotransmitter release (Sullivan, 2000; Elphick and Egertova, 2001). Recent evidence further suggests that endogenous cannabinoid compounds function as retrograde signaling molecules. Released postsynaptically, these endogenous cannabinoids are implicated in inhibition of presynaptic transmitter release, which can lead either to a 
suppression of inhibition (e.g., GABAergic synapses) or a suppression of excitation (e.g., glutaminergic synapses; Kreitzer and Regehr, 2001a, b; Ohno-Shosaku et al., 2001; Wilson and Nicoll, 2001).

Because the zenk response in NCM is activity dependent (Mello et al., 1992; Mello and Clayton, 1994), a selective CB1 receptor-mediated suppression of excitation within NCM, but not Field L, is the most parsimonious explanation for our results. If so, regional differences in the expression of $\mathrm{CB} 1$ in the neostriatum are a potential mechanism for such selectivity. Although we have used in situ hybridization to identify cellular CB1 mRNA expression in the caudal neostriatum at the level of HVC (a brain region involved in vocal control; Soderstrom and Johnson, 2000), portions of the neostriatum containing NCM and Field L were not specifically processed or examined. We are currently working to determine the distribution pattern of $\mathrm{CB} 1$ in the zebra finch CNS to assess differences in expression levels within the auditory telencephalon (e.g., high within NCM and low or absent within Field L).

A number of studies indicate that cannabinoids impair memory acquisition in mammals by suppressing excitation in the hippocampus, one consequence of which is that hippocampal neural activity remains below levels required for long-term potentiation (LTP; Terranova et al., 1995; Stella et al., 1997; Hampson and Deadwyler, 2000; Sullivan; 2000). That is, activation of CB1 receptors impairs LTP via inhibition of presynaptic calcium channels, thereby reducing excitatory neurotransmitter release below levels that are required to remove the magnesium block from postsynaptic NMDA receptors (Misner and Sullivan, 1999; Sullivan, 1999; Hoffman and Lupica, 2000). However, this view has been complicated recently by the observation that antagonism of CB1 receptors (by administration of SR141716A) can also inhibit LTP (Wilson and Nicoll, 2001). This effect appears to occur via blockade of an endogenous cannabinoidinduced suppression of GABA-ergic inhibition that normally contributes to the formation of LTP (Wilson and Nicoll, 2002). Thus, it appears that within the mammalian hippocampus cannabinoids can be involved in the suppression of both excitation and inhibition, with the location and timing of endogenous cannabinoid release being a key factor in determining the outcome on neuronal depolarization necessary for LTP.

Consistent with the inhibitory effects of cannabinoids on LTP and memory formation in the mammalian hippocampus, the present findings provide experimental support for the hypothesis that the habituation of zenk expression in NCM following repeated expo- sure to the same song reflects the formation of an auditory memory (see review in Clayton, 2000). That is, by using cannabinoid treatment to inhibit NCM zenk expression during 2 consecutive days of song exposure, we subsequently observed a "novel-like" NCM zenk response when birds were given vehicle and exposed to the song on a third day (see Fig. 6). One possibility is that the mechanisms that underlie the habituation of the NCM zenk response depend on the activation of zenk-mediated transcription when a song is heard for the first time (Ribeiro and Mello, 2000).

Together, our findings also suggest that endogenous cannabinoid signaling may be involved in the regulation of NCM zenk expression and the process of songbird auditory learning. NCM zenk expression is correlated with several forms of neuronal and behavioral plasticity in songbirds, such as experience-dependent changes in neuronal responsiveness to song playback, developmental changes in vocal behavior, and the fidelity of song learning by juveniles (Clayton, 1997, 2000; Bolhuis et al., 2000; Stripling et al., 2001), and as with LTP, a threshold level of neuronal depolarization is required for zenk expression (reviewed by Ribeiro and Mello, 2000). In this context, the present data provide a clear direction for future work. For example, because NCM zenk expression is correlated with the fidelity of song learning by juvenile zebra finches (Bolhuis et al., 2000), administration of a cannabinoid agonist to inhibit zenk expression during the period of auditory learning can be used to test for the behavioral consequences of normal versus impaired NCM zenk expression. Demonstration of endogenous cannabinoid signaling in NCM will require the development of techniques to detect and measure the synthesis and release of endocannabinoids in the zebra finch CNS, work that is currently underway by one of the authors (K.S.).

To our knowledge, the present data are the first to demonstrate selective cannabinoid modulation of perception-related neural activity in the vertebrate telencephalon. As such, they add a new perspective to emerging views about sites of action of CNS cannabinoid signaling. Interestingly, the idea that cannabinoids could influence cognitive function by selective alteration of perceptual processes is supported by the results of recent psychophysical studies in humans. Oral administration of cannabinoids to human subjects reduces/prevents reversal of binocular depth inversion to stereoscopically presented images, a task that depends on the integration of binocular sensory input (Leweke et al., 1999, 2000). It is possible that modulation of perceptual/integrative mechanisms is a 
key physiological role for endocannabinoid signaling in the vertebrate brain.

We are grateful to Pam Maras and Ross Henderson for experimental help and technical assistance, respectively. O.W. is a former American Psychological Association MFP Fellow in Neuroscience.

\section{REFERENCES}

Bolhuis JJ, Zijlstra GG, den Boer-Visser AM, Van Der Zee EA. 2000. Localized neuronal activation in the zebra finch brain is related to the strength of song learning. Proc Natl Acad Sci USA 97:2282-22825.

Bonke BA, Bonke D, Scheich H. 1979. Connectivity of the auditory forebrain nuclei in the guinea fowl (Numida meleagris). Cell Tissue Res 200:101-121.

Chaperon F, Thiebot MH. 1999. Behavioral effects of cannabinoid agents in animals. Crit Rev Neurobiol 13:243281.

Chew SJ, Mello C, Nottebohm F, Jarvis E, Vicario DS. 1995. Decrements in auditory responses to a repeated conspecific song are long-lasting and require two periods of protein synthesis in the songbird forebrain. Proc Natl Acad Sci USA 92:3406-3410.

Clayton DF. 1997. Role of gene regulation in song circuit development and song learning. J Neurobiol 33:5493471.

Clayton DF. 2000. The genomic action potential. Neurobiol Learn Mem 74:185-216.

Elphick MR, Egertova M. 2001. The neurobiology and evolution of cannabinoid signaling. Philos Trans R Soc Lond B Biol Sci 356:381-408.

Fortune ES, Margoliash D. 1995. Parallel pathways and convergence onto $\mathrm{HVc}$ and adjacent neostriatum of adult zebra finches (Taeniopygia guttata). J Comp Neurol 360: 413-441.

Hampson RE, Deadwyler SA. 2000. Cannabinoids reveal the necessity of hippocampal neural encoding for shortterm memory in rats. J Neurosci 20:8932-8942.

Herkenham M, Lynn AB, Little MD, Johnson MR, Melvin LS, de Costa BR, Rice KC. 1990. Cannabinoid receptor localization in brain. Proc Natl Acad Sci USA 87:19321936.

Hoffman AF, Lupica CR. 2000. Mechanisms of cannabinoid inhibition of GABA(A) synaptic transmission in the hippocampus. J Neurosci 20:2470-2479.

Hohmann AG, Martin WJ, Tsou K, Walker JM. 1995. Inhibition of noxious stimulus-evoked activity of spinal cord dorsal horn neurons by the cannabinoid WIN 55,212-2. Life Sci 56:2111-2118.

Kreitzer AC, Regehr WG. 2001a. Retrograde inhibition of presynaptic calcium influx by endogenous cannabinoids at excitatory synapses onto purkinje cells. Neuron 29: 717-727.

Kreitzer AC, Regehr WG. 2001b. Cerebellar depolarization- induced suppression of inhibition is mediated by endogenous cannabinoids. J Neurosci 21:RC174.

Kruse AA, Stripling R, Clayton DF. 2000. Minimal experience required for immediate-early gene induction in zebra finch neostriatum. Neurobiol Learn Mem 74:179184.

Leweke FM, Schneider U, Radwan M, Schmidt E, Emrich HM. 2000. Different effects of nabilone and cannabidiol on binocular depth inversion in man. Pharmacol Biochem Behav 66:175-181.

Leweke FM, Schneider U, Thies M, Munte TF, Emrich HM. 1999. Effects of synthetic delta9-tetrahydrocannabinol on binocular depth inversion of natural and artificial objects in man. Psychopharmacology (Berlin) 142:230-235.

Mello CV, Clayton DF. 1994. Song-induced ZENK gene expression in auditory pathways of songbird brain and its relation to the song control system. J Neurosci 14:66526666.

Mello CV, Nottebohm F, Clayton DF. 1995. Repeated exposure to one song leads to a rapid and persistent decline in an immediate early gene's response to that song in the zebra finch telencephalon. J Neurosci 15:6919-6925.

Mello CV, Ribeiro S. 1998. ZENK protein regulation by song in the brain of songbirds. J Comp Neurol 393:426438.

Mello CV, Vicario DS, Clayton DF. 1992. Song presentation induces gene expression in the songbird forebrain. Proc Natl Acad Sci USA 89:6818-6822.

Misner DL, Sullivan JM. 1999. Mechanism of cannabinoid effects on long-term potentiation and depression in hippocampal CA1 neurons. J Neurosci 19:6795-6805.

Ohno-Shosaku T, Maejima T, Kano M. 2001. Endogenous cannabinoids mediate retrograde signals from depolarized postsynaptic neurons to presynaptic terminals. Neuron 29:729-738.

Ribeiro S, Cecchi GA, Magnasco MO, Mello CV. 1998. Toward a song code: evidence for a syllabic representation in the canary brain. Neuron 21:59-71.

Ribeiro S, Mello CV. 2000. Gene expression and synaptic plasticity in the auditory forebrain of songbirds. Learn Mem 7:235-243.

Soderstrom K, Johnson F. 2001. Zebra finch CB1 cannabinoid receptor: pharmacology and in vivo and in vitro effects of activation. J Pharmacol Exp Ther 297:189197.

Soderstrom K, Leid M, Moore FL, Murray TF. 2000. Behavioral, pharmacological and molecular characterization of an amphibian cannabinoid receptor. J Neurochem 75 : 413-423.

Soderstrom K, Johnson F. 2000. CB1 cannabinoid receptor expression in brain regions associated with zebra finch song control. Brain Res 85 7:151-157.

Sullivan JM. 1999. Mechanisms of cannabinoid-receptormediated inhibition of synaptic transmission in cultured hippocampal pyramidal neurons. J Neurophysiol 82:1286-1294.

Sullivan JM. 2000. Cellular and molecular mechanisms 
underlying learning and memory impairments produced by cannabinoids. Learn Mem 7:132-139.

Stella N, Schweitzer P, Piomelli D. 1997. A second endogenous cannabinoid that modulates long-term potentiation. Nature 388:773-778.

Stripling R, Kruse AA, Clayton DF. 2001. Development of song responses in the zebra finch caudomedial neostriatum: role of genomic and electrophysiological activities. J Neurobiol 48:163-180.

Stripling R, Volman SF, Clayton DF. 1997. Response modulation in the zebra finch neostriatum: relationship to nuclear gene regulation. J Neurosci 17:3883-3893.

Terranova JP, Michaud JC, Le Fur G, Soubrie P. 1995. Inhibition of long-term potentiation in rat hippocampal slices by anandamide and WIN55212-2: reversal by SR141716 A, a selective antagonist of CB1 cannabinoid receptors. Naunyn Schmiedebergs Arch Pharmacol 352:576-579.
Tsou K, Lowitz KA, Hohmann AG, Martin WJ, Hathaway CB, Bereiter DA, Walker JM. 1996. Suppression of noxious stimulus-evoked expression of Fos protein-like immunoreactivity in rat spinal cord by a selective cannabinoid agonist. Neuroscience 70:791-798.

Vates GE, Broome BM, Mello CV, Nottebohm F. 1996. Auditory pathways of caudal telencephalon and their relation to the song system of adult male zebra finches. J Comp Neurol 366:613-642.

Whitney O, Soderstrom K, Johnson F. 2000. Post-transcriptional regulation of zenk expression associated with zebra finch vocal development. Mol Brain Res 80:279-290.

Wilson RI, Nicoll RA. 2001. Endogenous cannabinoids mediate retrograde signaling at hippocampal synapses. Nature 410:588-592.

Wilson RI, Nicoll RA. 2002. Endocannabinoid signaling in the brain. Science 296:678-682. 